\title{
Health care expenditures and longevity: is there a Eubie Blake effect?
}

\author{
Friedrich Breyer • Normann Lorenz • \\ Thomas Niebel
}

\begin{abstract}
It is still an open question whether increasing life expectancy as such causes higher health care expenditures (HCE) in a population. According to the "red herring" hypothesis, the positive correlation between age and HCE is exclusively due to the fact that mortality rises with age and a large share of HCE is caused by proximity to death. As a consequence, rising longevity through falling mortality rates may even reduce HCE. However, a weakness of many previous empirical studies is that they use cross-sectional evidence to make inferences on a development over time. In this paper, we analyse the impact of rising longevity on the trend of HCE over time by using data from a pseudo-panel of German sickness fund members over the period 1997 2009. Using (dynamic) panel data models, we find that age, mortality and 5-year survival rates each have a positive impact on per-capita HCE. Our explanation for the last finding is that physicians treat patients more aggressively if the results of these treatments pay off over a longer time span, which we call "Eubie Blake effect". A simulation on the basis of an official population forecast for Germany is used to isolate
\end{abstract}

\section{F. Breyer}

Fachbereich Wirtschaftswissenschaften, Universität Konstanz,

Fach D 135, 78457 Konstanz, Germany

e mail: friedrich.breyer@uni konstanz.de

N. Lorenz $(\bowtie)$

Universität Trier, Universitätsring 15, 54286 Trier, Germany

e mail: lorenzn@uni trier.de

T. Niebel

Zentrum für Europäische Wirtschaftsforschung (ZEW), Postfach

1034 43, 68034 Mannheim, Germany

e mail: niebel@zew.de the effect of demographic ageing on real per-capita HCE over the coming decades. We find that, while falling mortality rates as such lower HCE, this effect is more than compensated by an increase in remaining life expectancy so that the net effect of ageing on HCE over time is clearly positive.

Keywords Health care expenditures - Ageing · Longevity $\cdot 5$-year survival rate

JEL Classification H51 $\cdot$ J11 $\cdot$ I19

If I'd known I was going to live this long,

I would have taken better care of myself.

(Eubie Blake on his alleged 100th birthday)

\section{Introduction}

The ageing of populations in most OECD countries will place an enormous burden on tax payers over the coming decades. Given this demographic change, previous fiscal policies in several of these countries were deemed unsustainable, and major reforms of social insurance systems have been enacted, in particular with respect to public pension and long-term care financing systems. However, what remains unclear is whether population ageing also jeopardizes the sustainability of social health insurance $[15,16]$. While there is no doubt that the revenue side of these systems will suffer from the shrinking size of future taxpayer generations, it is not so clear if rising longevity will place an extra burden on the expenditure side. If so, additional reforms of these 
systems would be necessary to guarantee the sustainability of these systems, such as introducing more funding or limiting the generosity of benefits.

The impact of population ageing on health care expenditures (HCE hereafter) has been heavily debated over the last decade. ${ }^{1}$ That the positive association between age and HCE is primarily due to the high cost of dying and rising mortality rates with age was first observed by Fuchs [14]. Subsequently, Zweifel et al. [36] have coined the term "red herring" to characterize the erroneous conclusion from the cross-sectional correlation between age and HCE that population ageing due to increasing longevity implies rising country level HCE over time. As counter-evidence they showed that in individual data when controlling for proximity to death calendar age is not even a significant predictor of health care costs.

Although this early study suffered from its focus on patients in their last year of life, subsequent studies by several authors such as Seshamani and Gray [26], Zweifel et al. [37], Werblow et al. [34] and Felder et al. [13] confirmed the red herring hypothesis by demonstrating that, even for persons who survived for at least four more years, there is at most a small age gradient in HCE, whereas the costs of the last year of life even tend to decrease with age at death [7, 13]. The latter finding is explained by the tendency of physicians to treat patients who have lived beyond a "normal life-span" less aggressively than younger patients with the same diagnosis and survival chances. In this vein, Miller [23] shows by simulation that, based on a negative relationship between age at death and death-related costs, an increase in longevity will dampen the growth of HCE.

However, an important weakness of almost all studies in the related literature is their reliance on cross-sectional expenditure data. Therefore, in drawing inferences from these studies on the development of HCE over time, proponents of the red herring hypothesis commit the same error of which they accuse their opponents (i.e. those who think that population ageing increases health spending because per-capita expenditures increase with age). In particular, they overlook the fact that increasing longevity not only means that 30 years from now average age at death will be higher but also that people at a certain age say, 80 will on average have more years to live than present 80 year olds.

If individuals have more years to live, this will have an influence on their HCE for two reasons. Firstly, there is evidence that physicians as prime decision makers, who have to allocate scarce resources among their patients (e.g. in a hospital), base their decisions on the benefit to the

\footnotetext{
${ }^{1}$ A recent survey can be found in Karlsson and Klohn [22].
}

patient [19], where, of course, the patient's expected longevity is an important determinant of this benefit. ${ }^{2}$ This effect will lead to physician behavior similar to "age-based rationing" of health care services when the notion of a "normal life span" [6,9] shifts over time with rising longevity. ${ }^{3}$ However, if physicians have a better indicator than calendar age, i.e. if they can observe "biological age", they will certainly use the latter, which is just the mirror image of "expected remaining lifetime".

Secondly, when a major medical treatment such as implanting an artificial hip is decided upon, the physician and the patient himself will weigh the risks involved against the potential gains, which again depend upon the general health status of the patient for which his life expectancy is a proxy. In that respect, the physician and the patient will behave in a way described in the famous quotation from Eubie Blake, i.e. more will be spent on those patients who will profit from the treatment for a longer time period. ${ }^{4}$

This reasoning suggests that the relationship between "life expectancy" or "time to death" and HCE is nonmonotonic, and it is exactly this non-monotonic relationship on which we focus in this study. In the very last years of life, a lower value of these variables indicates worse health and therefore higher HCE, e.g. for emergency treatment and heroic efforts to avoid the unavoidable. In individual data, this effect can be captured by a dummy for the "last year of life" and in group data by the share of persons who died in the particular year, i.e. the mortality rate. In contrast, when time to death is longer (say, between 5 and 10 years), a higher value indicates a better chance to benefit from elective surgery and other potentially risky procedures for a longer time and thus leads to higher HCE, as argued above; in group data, this "Eubie Blake effect" can be captured by including a measure for longevity such as the remaining life expectancy.

To test whether there is a "Eubie Blake effect", it is desirable to study how rising life expectancy in a population has affected HCE over time. This requires a dataset that comprises this variable, or an indicator of it, and covers several years.

To our knowledge, there have only been three previous studies that have used life expectancy as an explanatory

\footnotetext{
${ }^{2}$ For instance, one criterion in organ allocation is expected organ functioning duration.

3 The empirical literature shows that some physicians use age as a prioritisation criterion in allocating scarce health care resources; for an overview, see Strech et al. [30].

${ }^{4}$ Fang et al. [12] attribute the same quotation to the baseball star Mickey Mantle and speak of a "Mickey Mantle effect". However, it is quite clear that Mantle did not invent the phrase, but quoted the football player Bobby Lane, who died in late 1986 and may well have known the statement by Blake, which had been made in February 1983.
} 
variable in a regression equation for HCE, viz. [2, 27, 38], of which the first used individual-level data and the other two population-level data.

Shang and Goldman [27] used a rotating panel of more than 80,000 Medicare beneficiaries and predicted the life expectancy for each individual, based on age, sex, race, education and health status, and then performed a nonlinear-least-squares estimation of individual HCE. In this equation, predicted life expectancy turned out to be highly significant and negative, whereas age became insignificant when this variable was included. The interpretation of this result is, however, very similar to other studies in the red herring literature because predicted life expectancy, if the value is low (say, a few years), is a proxy for time to death.

Zweifel et al. [38], in contrast, used a panel of 17 OECD countries over a period of 30 years (1970 2000) and tried to jointly explain HCE and life expectancy. As one of the determinants of $\mathrm{HCE}$, they constructed an artificial variable by multiplying "life expectancy at 60" (averaged over both sexes) with the share of persons over 65 in the total population. The predicted value of this variable turned out to be a significantly positive determinant of HCE. A problem with this result is that it does not allow the disentangling of the effect of life expectancy itself from the effect of the old age dependency ratio, which is also a function of past birth rates.

Bech et al. [2] considered per-capita HCE for a panel of 15 EU member states over the period 1980 to 2003 and found that both mortality and remaining life expectancy at age 65 have a significant positive effect on HCE in the following year. They then calculated long-run elasticities of HCE with respect to these variables and found a positive value only for life expectancy, so that a linear increase in life expectancy at 65 is associated with an exponential growth in per-capita HCE. Being a "macro" study, the work by Bech et al. leaves open the question of whether the same relationship can still be found when disaggregated data are used such as HCE by age group.

In this paper, we aim to disentangle the two effects of rising longevity, i.e. the "direct" effect of decreasing HCE (at a certain age) due to a falling mortality rate (at that age) and the "indirect" effect of increasing HCE due to an increase in the remaining life expectancy (at that age and conditional on surviving until the end of the year). To do so, we employ a measure for remaining life expectancy which is especially common among physicians: (expected) 5 -year survival rates. In medical studies, in particular those concerned with specific diseases, this measure is used instead of life expectancy as such. ${ }^{5}$

\footnotetext{
${ }^{5}$ See, e.g., the fact sheet on cancer edited by the National Institutes of Health, which is published online at http://report.nih.gov/ nihfactsheets/Pdfs/Cancer(NCI).pdf.
}

Assessing the impact of life expectancy on total HCE in a country requires the use of population-level data for two reasons: firstly, for individuals, life expectancy is not welldefined let alone observable, while, secondly, the red herring effect even though many authors use individual data to make their point in this debate is focused exactly on the question of whether population ageing due to increasing life expectancies will lead to increasing HCE in $a$ country; whether this is the case not only depends on individual demand but also on supply side factors like government interventions or measures taken by the sickness funds. ${ }^{6}$ Hence, population-level data should be used to scrutinize the validity of the red-herring theory.

The dataset we employ is a pseudo-panel of sickness fund members in Germany, which was originally collected for calculating age- and sex-specific (average) HCE for purposes of risk adjustment. This dataset, which covers the years 1997 2009, is merged with data on mortality rates published annually by the Human Mortality Database.

To determine the impact of longevity, we estimate (dynamic) panel data models, while to disentangle age, period and cohort effects, we apply the Intrinsic Estimator [35], which is a special case of a partial least squares regression [31]. We then use the estimated relationship to show the effect of an increase in survival rates according to official statistics on average HCE. We find that, while falling mortality rates as such lower HCE, this effect is more than compensated by an increase in remaining life expectancy so that the net effect of ageing on HCE over time is clearly positive.

The remainder of this paper is organized as follows. In the next two sections, we state the theoretical hypotheses to be tested and then describe the data. In the fourth and fifth sections we present the estimation strategy and regression results. In the sixth section we perform the simulation of the future development of HCE.

\section{Testable hypotheses}

The main focus of this paper will be the effect of "population ageing", expressed by falling mortality rates and increasing life expectancy, on average HCE of a population group characterized by age and gender. However, age and time will also be used as explanatory variables in the regression. The following theoretical predictions are derived from the literature and will be tested in the empirical estimation:

Age According to more "traditional" theory, HCE will be decreasing with age in the age range 020 , stay

\footnotetext{
${ }^{6}$ This point is also made by van Baal and Wong [32].
} 
approximately constant between 20 and 60 and will be increasing with age for age above 60 . In contrast, the alternative hypothesis on which the red herring claim is based states that HCE will be independent of age for age above 20 .

Time HCE will be increasing over time due to medical progress.

Mortality As, for individuals, expenditures are especially high in the last year of life ("cost-of-dying effect"), average $\mathrm{HCE}$ of a population group will be increasing in the mortality rate of the group.

Life expectancy Holding the mortality rate of an age group constant, HCE of this group will be increasing in the remaining life expectancy within the group as more resources will be spent on patients who have "more to gain" from an intervention. This "Eubie Blake effect" is especially important for older patients.

\section{Data}

Data sources

The data we use in this study come from three different sources. Our estimation dataset comprises data of the first and second source; the simulation uses data of the third source.

Data on HCE were provided by the German Federal (Social) Insurance Office ("Bundesversicherungsamt", BVA). To determine the risk adjustment payments for the statutory sickness funds, each year the BVA collects data on all expenditures covered by the sickness funds for all individuals insured in the social health insurance system. ${ }^{7}$ These data comprise eight major expenditure categories: ambulatory care, dental care, prescription drugs, inpatient care, medical supplies and equipment, sick-pay, dialysis and vaccinations. ${ }^{8}$ Based on this census, the BVA calculates the average yearly HCE for all sickness fund members, separately for each age-sex group; these averages are then published as daily HCE. The official risk adjustment data, which can be found on the BVA's website, are smoothed. For our study, we use the unsmoothed data which were provided to us by the BVA. ${ }^{9}$ Since we want to focus on health care expenditures, we exclude expenditures for sick-pay. The dataset also contains the number of individuals in each age-sex group; these data are given as

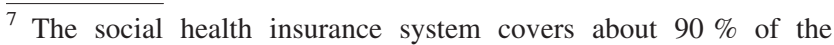
population in Germany.

${ }^{8}$ Expenditures for long term care are not covered under Social Health Insurance.

9 We thank Dirk Göpffarth, the Head of the Risk Adjustment Unit at BVA, for making this dataset available to us.
}

number of person-days, i.e., the number of insured times the average number of days per year an individual of this age-sex group is insured. The highest age group in this dataset contains all individuals of age 90 and above (along with their average HCE). Since we have no information about the age distribution within this group, we could not compute their average mortality and survival rate. We therefore drop this group, which amounts to a loss of $0.71 \%$ of all person-days.

Data on age- and sex-specific mortality rates are taken from the Human Mortality Database [18]. These data apply to the German population as a whole and not only to sickness fund members. Since the omitted group, the privately insured, have on average higher incomes, and life expectancy is positively associated with income in Germany [5, 33], the population-based life expectancy is somewhat higher than the true life expectancy of sickness fund members, but this error should be rather small given that sickness fund members account for about $90 \%$ of the German population.

The third source of data, which will be used for simulating the demographic effect on HCE, is the German Statistical Office, which publishes forecasts on the size and composition of the population in Germany over the following decades. The most recent one is the " 12 th coordinated population projection" [28]. In addition, the Office provided estimates of the development of age-specific mortality rates for the period until 2060. From these data, we calculated the time paths of age-specific survival rates. Of the two published forecasts, the one denoted the "most likely one" by the Office and the one with an even stronger increase in longevity, we use the "most likely one".

\section{Variables}

Throughout this paper, we use the 5-year survival rate of each age group as our measure of "life expectancy" because it is a familiar concept for physicians. Technically, the 5-year survival rate $S R 5$ at age $a$ in year $t$, conditional on surviving at least until the end of year $t$, is calculated by multiplying the 1-year survival rates (i.e. one minus the mortality rate) of age groups $a+1, a+2, \ldots, a+5$ in year $t$. This corresponds to the usual way remaining life expectancy for an age group is calculated. Note that the mortality rate of age group $a$ in year $t$ does not enter the calculation of the 5-year survival rate of this age group in year $t$. We can therefore indeed hold the mortality rate of an age group constant, while varying the remaining life expectancy, as formulated in the last of the four hypotheses.

For the following reason, we do not use the 5-year survival rate $S R 5$ as such but a predicted value of it. We argued that a physician will take the 5-year survival rate into account when deciding whether to perform an 
Table 1 Descriptive statistics for the variables Age, Cohort, HCE, MORT and SR5

\begin{tabular}{|c|c|c|c|c|c|c|c|c|}
\hline & \multicolumn{4}{|l|}{ Men } & \multicolumn{4}{|l|}{ Women } \\
\hline & Mean & SD & Min & Max & Mean & SD & Min & Max \\
\hline Age & 44.5 & 25.99 & 0 & 89 & 44.5 & 25.99 & 0 & 89 \\
\hline Cohort & 1958.5 & 26.26 & 1908 & 2009 & 1958.5 & 26.26 & 1908 & 2009 \\
\hline$H C E$ & 6.2437 & 4.7329 & 1.7812 & 17.6005 & 6.1312 & 3.8728 & 1.5020 & 15.7070 \\
\hline MORT & 0.0233 & 0.0437 & 0.00007 & 0.2275 & 0.0153 & 0.0321 & 0.00005 & 0.1711 \\
\hline SR5 & 0.8785 & 0.2021 & 0.1687 & 0.9996 & 0.9117 & 0.1685 & 0.2603 & 0.9997 \\
\hline
\end{tabular}

expensive or risky procedure. However, during the year $t$, the physician does not know the 5-year survival rate $S R 5_{c, a, t}$, where $c$ denotes cohort and $a$ denotes age. $S R 5_{c, a, t}$ is a measure derived from the mortality rates in the same year, which are not known until the end of year $t$. It is therefore an informed guess of the survival rate the physician will have in mind. One possible proxy for this guess would be the value of this variable in the previous year (for the same age), $S R 5_{c-1, a, t-1}$, but this is certainly not the best choice. Firstly, survival rates are increasing over time, so there would be a systematic downward bias in this proxy, and, secondly, the survival rate in a particular year $t-1$ is derived from the mortality rates of five different age groups in this particular year $t-1$, which, to some degree, also depend upon singular events such as a flu epidemic or a heat wave. These singular events will, however, have no (or only a minor) effect on the informed guess of the physician; rather, it will depend on his or her experience over a longer time period. Therefore, we use a linear projection of the survival rate (for the same age) of the previous 5 years. ${ }^{10}$ In the following, whenever we use the symbol $S R 5$, we refer to this prediction of the 5-year survival rate. ${ }^{11}$

In our analysis, we use the following variables:

- $H C E_{c, a, t}$ (dependent variable), the average annual health care expenditures covered by the sickness funds except for sick pay of all insured persons in cohort $c$ of age $a$ in year $t$, expressed as average daily expenditures and converted to Euros of 2009 using the consumer price index;

\footnotetext{
$\overline{10}$ Technically, we run a regression of $\left(S R 5_{c-5, a, t-5}, \ldots, S R 5_{c-1, a, t-1}\right)^{\prime}$ on a constant and a linear time trend, i.e.

$S R 5_{c-\tau, a, t-\tau} \quad \mu_{0} \quad \mu_{1} \tau+\varepsilon$ for $\tau \quad 1, \ldots, 5$,

and determine the prediction as $\widehat{S R 5}_{c, a, t} \quad \hat{\mu}_{0} \quad \hat{\mu}_{1} \cdot 0 \quad \hat{\mu}_{0}$. For each prediction, a separate regression is performed. As these equations are estimated for every age, there is implicitly an interaction between age and year in this estimation. In contrast, there is no age year interaction term in the equation for HCE; this difference is used for identification.

11 A possible concern might be that the mortality rate and SR5 are highly correlated and thus the effect of the two variables cannot be disentangled empirically. However, this is not the case; we return to this issue in the fifth section.
}

- $M O R T_{c, a, t}$, the mortality rate, i.e. the share of persons in cohort $c$ of age $a$ in year $t$ who have died within that year;

- $S R 5_{c, a, t}$, the (predicted) 5-year survival rate of all persons in cohort $c$ of age $a$ in year $t$, conditional on surviving until the end of the current year; ${ }^{12}$

- a set of dummy variables $A g e_{a}$ for each age $a$ with $a=0, \ldots, 89$;

- a set of dummy variables Cohort for $_{c}$ each cohort $c$ with $c=1908, \ldots, 2009$, (the year in which the person was born);

- a set of dummy variables Year $_{t}$ for each year $t$ with $t=1997, \ldots, 2009$.

Because each entry of our dataset contains the average values of a particular age-sex group, it is a "pseudo-panel" in the sense of Deaton [11]. It comprises the period 1997 2009. As there are 90 age groups (0 89) for men and women separately, the total number of observations is 2,340. Table 1 contains descriptive statistics on the dataset. Since we perform the estimations separately for men and women, we also present these statistics separately. For men, average HCE per day range from $€ 1.78$ (at age 3 in 1997 ) to $€ 17.60$ (at age 89 in 2009).

Table 2 presents 5-year survival rates for selected age groups in the base year 1997 and their increase over time until 2009. The table shows that, even within this relatively short time span, for some age groups 5-year survival rates increase considerably: up to 9 percentage points for men and up to 5.6 percentage points for women.

\section{Estimation strategy}

Main specification

To describe the estimation strategy, we begin with the general specification

\footnotetext{
12 For the robustness checks, we also use the variables $S R 2_{c, a, t}, S R 3_{c, a, t}, \ldots S R 10_{c, a, t}$, i.e., the predicted 2 year survival rate, 3 year survival rate, and so on.
} 
Table 2 Age sex specific 5 year survival rates: level in 1997 (\%) and increase $\Delta$ from 1997 to 2009 (percentage points)

\begin{tabular}{|c|c|c|c|c|}
\hline \multirow[t]{3}{*}{ Age } & \multicolumn{2}{|l|}{ Men } & \multicolumn{2}{|c|}{ Women } \\
\hline & \multicolumn{2}{|l|}{$S R 5$} & \multicolumn{2}{|l|}{ SR5 } \\
\hline & 1997 & $\Delta$ & 1997 & $\Delta$ \\
\hline 60 & 91.1 & 2.4 & 95.9 & 0.8 \\
\hline 65 & 86.1 & 4.3 & 93.2 & 1.9 \\
\hline 70 & 79.1 & 5.9 & 88.3 & 3.4 \\
\hline 75 & 67.9 & 6.9 & 79.5 & 4.6 \\
\hline 80 & 51.2 & 9.0 & 64.6 & 5.6 \\
\hline 85 & 31.6 & 8.6 & 43.6 & 4.7 \\
\hline 90 & 14.0 & 4.0 & 22.1 & 1.1 \\
\hline
\end{tabular}

$H C E_{c, a, t}=g(c, a, t)+\beta_{1} \operatorname{MORT}_{c, a, t}+\beta_{2} S R 5_{c, a, t}+u_{c, a, t}$,

where $g$ captures the effects of cohort, age and time, and $u_{c, a, t}$ denotes the error term. There is no dummy variable included for gender because we perform all estimations separately for men and women, since as is well known the age profiles of HCE have rather different shapes for men and women.

The specification in Eq. 1 suffers from the familiar problem of linear dependence since age equals year minus cohort:

$a=t-c$.

Because we want to estimate the effects of cohort, age and time in a flexible manner, we follow the dummy-variables approach and set

$g(c, a, t)=\beta_{0}+\sum_{c} \gamma_{c}$ Cohort $_{c}+\sum_{a} \alpha_{a}$ Age $_{a}+\sum_{t} \delta_{t}$ Year $_{t}$,

where, in each set of dummy variables, one variable is omitted because of the constant term.

Of course, the problem of linear dependence also applies to the dummy variables specification. There are, in principle, two strategies for dealing with this problem. The first one is to drop one of the variables (or set of dummies for) age, cohort or time and, for example, estimate a model with only age and year dummies. As our dataset is a pseudopanel in which the "individuals" are cohorts, this variable cannot be dropped in our analysis. Obviously, the age effect and the time effect cannot be dropped, either.

The second strategy is to impose a restriction on the coefficients $\gamma, \alpha$ and $\delta .{ }^{13}$ One can distinguish two ways to do so. In most cases, one of the coefficients is set to zero, or

\footnotetext{
13 Of course, dropping one of the variables means imposing the restriction that all coefficients of this variable are zero. However, since this is usually not made explicit, we mention it as a separate way to deal with the problem of linear dependence.
}

two usually, but not necessarily, adjacent coefficients are set equal. For example, with $\delta_{2000}=\delta_{2001}$, it is assumed that there is no time effect going from the year 2000 to 2001; with $\alpha_{20}=\alpha_{21}$, it is assumed that 20 and 21 year olds have equal health care expenditures. If one can be confident that the assumption is valid, this will correctly disentangle the age, period and cohort effects.

However, as shown by Yang et al. [35], the resulting estimates can be seriously misleading if the assumption is not warranted. In fact, in our data, the estimates are very sensitive to which two coefficients are set equal: If, for example, we assume $\alpha_{23}=\alpha_{24}$, the year dummies indicate a positive time trend; this reverses if we set $\alpha_{24}=\alpha_{25}$, so that HCE are estimated to decrease over time. For $\alpha_{25}=\alpha_{26}$, the time trend is again positive. This lack of robustness is a strong reason for discarding this solution to the linear dependence problem.

The second way to impose a restriction on $\gamma, \alpha$ and $\delta$ is the following. The problem in estimating Eq. 1 with $g(a, c, t)$ replaced by the set of dummy variables as shown in Eq. 2 is that the well-known least squares formula $\left(X^{\prime} X\right)^{-1} X^{\prime} H C E$, (where $X$ is the matrix containing all the explanatory variables) cannot be applied because $X^{\prime} X$ is a singular matrix that cannot be inverted. However, an infinite number of generalized inverse matrices exist. A particular one is the Moore-Penrose inverse, which, as [31] point out, is to be preferred, because the results using this Moore-Penrose inverse correspond to the results of both a Principal Component Regression and a Partial Least Squares Regression if the maximum number of components is used; in addition, they also coincide with the result of the Intrinsic Estimator proposed by Yang et al. [35]. This is the approach we follow in this study. ${ }^{14}$

Before we proceed, it is important to emphasize that the restriction imposed on $\gamma, \delta$ and $\alpha$ has no influence on the coefficients of all the other covariates: Regardless of whether one coefficient is set equal to zero, or two coefficients are set equal, or the Intrinsic Estimator is used, $\hat{\beta}_{1}$ and $\hat{\beta}_{2}$ will always be the same. This means that the coefficients we are most interested in are not at all affected by how the linear dependence problem is solved. As a consequence, the predicted values $\widehat{H C E}$ also do not depend on which restriction is imposed. ${ }^{15}$

\footnotetext{
${ }^{14}$ Because of the way the Intrinsic Estimator is implemented in Stata's apc ie command, in practice the estimates of the Intrinsic Estimator may differ slightly from the results of the partial least squares regression. In our data, we find the difference between the estimates using the Partial Least Squares Regression procedure of the software package R and Stata's apc ie command to be negligible. Since we perform the other regressions in Stata, we present the results for the Intrinsic Estimator.

15 This is an application of the Frisch Waugh Lowell Theorem, see Davidson and MacKinnon [10], chapter 1. No matter which restriction is imposed on $\gamma, \delta$ and $\alpha$, the subspace spanned by Eq. 2 is always the same.
} 
As our main specification, we therefore use the Intrinsic Estimator to estimate

$$
\begin{aligned}
H C E_{c, a, t}= & \beta_{0}+\sum_{c} \gamma_{c} \text { Cohort }_{c}+\sum_{a} \alpha_{a} \text { Age }_{a}+\sum_{t} \delta_{t} \text { Year }_{t} \\
& +\beta_{1} \operatorname{MORT}_{c, a, t}+\beta_{2} \operatorname{SR}_{c, a, t}+u_{c, a, t} .
\end{aligned}
$$

To have a comparison model as used by the proponents of the red herring hypothesis we also estimate a model with only MORT (i.e. Eq. (3) without SR5). We also present the results with only $S R 5$ to show that the coefficients are stable and that the effects of these two variables can indeed be disentangled. Throughout the text (and in the tables containing the results), we refer to the model with only MORT as regression (1), the model with only SR5 as regression (2), and the model with both MORT and $S R 5$ as regression (3).

As the dataset is a pseudo panel, and the respective cohort-age cells contain different numbers of observations, the results from the (fixed effects) panel estimation may not be efficient and have to be weighted by the square root of the cohort size (see Deaton [11]). As in our panel the cohort size is not constant over time, we could use different weights for each cohort-age cell. However, Inkmann et al. [21] show that estimation results can be unstable if the cohort size differs considerably and therefore propose weighting by the average weight for each cohort. We therefore use weights that do not differ in the time dimension. In addition, in all regressions we present, we allow for autocorrelation of the error terms by clustering at the cohort level. ${ }^{16}$

\section{Robustness checks}

As a first robustness check, we test whether our results critically depend on choosing the 5-year survival rate (instead of any other $n$-year survival rate) as our proxy for how long a patient benefits from a treatment. We examine this question by re-estimating the model with $S R 5$ replaced by different $n$-year survival rates $S R n$.

A second issue is that one could argue that the variable MORT not only measures the actual share of individuals within an age bracket who die in a particular year but that it is also a proxy for mortality risk. If this mortality risk increases, $H C E$ should go up, especially if the remaining life expectancy is large. This would call for also including an interaction term MORT $\times S R 5$. However, these two variables are mutually exclusive at the individual level. One way to capture that the effect of MORT may depend on

\footnotetext{
$\overline{16}$ Results are very similar when clustering at the age or year level.
}

the level of the remaining life expectancy is to interact MORT with age. ${ }^{17}$

We then consider the case that the true relationship may be dynamic so that there is persistence in HCE. If, e.g., a particularly large share of individuals in an age bracket develops a chronic condition (like diabetes or COPD), this will not only raise $H C E$ in the current year but also in the following year (for this cohort). ${ }^{18}$ To account for this problem, we estimate the following dynamic panel model:

$$
\begin{aligned}
H C E_{c, a, t}= & \sum_{c} \beta_{c} \text { Cohort }_{c}+\sum_{a} \alpha_{a} \text { Age }_{a}+\sum_{t} \delta_{t} \text { Year }_{t} \\
& +\phi H C E_{c, a} 1, t 1+\gamma_{1} \text { MORT }_{c, a, t} \\
& +\gamma_{2} \operatorname{SR}_{c, a, t}+u_{c, a, t} .
\end{aligned}
$$

We estimate Eq. 4 by GMM, (where the fixed effects correspond to the cohort dummies), using both the difference-GMM-estimator by Arellano and Bond [1] and the system-GMM-estimator by Blundell and Bond [3], and show the results both for MORT to be either predetermined or endogenous. We refer to the four GMM specifications as regressions (4) to (7).

As a final robustness check, we consider the case that the variables may be non-stationary so that there may be the problem of spurious regression. For this reason, we tested for unit roots. Since these tests do not reject non-stationarity in the explanatory variables although they do so for the dependent variable $H C E$ we also estimate all models in first (and second) differences, i.e. with HCE, MORT and $S R 5$ replaced by $\triangle H C E, \triangle M O R T$ and $\triangle S R 5$, (and $\Delta^{2} H C E, \Delta^{2} M O R T$ and $\left.\Delta^{2} S R 5\right)$. We refer to the regressions in first differences as regressions (11) to (17), and in second differences as regressions (21) to (27). ${ }^{19}$

\section{Regression results}

Main specification

In Table 3, we present the regression results for our main specification, separately for men and women. In column (1), results from the Intrinsic Estimator for the model with age, cohort and year dummies and MORT is presented; the results with $S R 5$, but without MORT can be found in column (2). Column (3) contains the results with both MORT and SR5 as defined in regression equation (3).

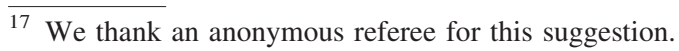

18 Another way to deal with this would be to include proxy variables; however, such variables will be difficult to find because they would have to be recorded in an age specific way.

19 Regression (1) in first differences is referred to as regression (11), and in second differences as regression (21), and so on.
} 
Table 3 Regression results using the Intrinsic estimator

Dependent variable: daily HCE. Standard errors clustered at the cohort level

Standard errors in parentheses; $* * *(* *, *)$ : significant at $\alpha$ $0.01(0.05,0.1)$

\begin{tabular}{|c|c|c|c|c|c|c|}
\hline & \multicolumn{3}{|l|}{ Men } & \multicolumn{3}{|l|}{ Women } \\
\hline & (1) & (2) & (3) & (1) & (2) & (3) \\
\hline$M O R T$ & $\begin{array}{l}68.26 \text { *** } \\
(11.88)\end{array}$ & & $\begin{array}{l}58.30 * * * \\
(11.23)\end{array}$ & $\begin{array}{l}27.22 * \\
(14.19)\end{array}$ & & $\begin{array}{l}26.24 * * * \\
(7.87)\end{array}$ \\
\hline SR5 & & $\begin{array}{l}41.72 * * * \\
(8.47)\end{array}$ & $\begin{array}{l}36.45 * * * \\
(7.31)\end{array}$ & & $\begin{array}{l}42.79 * * * \\
(4.11)\end{array}$ & $\begin{array}{l}42.69 * * * \\
(3.90)\end{array}$ \\
\hline
\end{tabular}

Figure 3 shows the positive time trend in HCE. It also shows the dampening impact of a major health care reform that took effect in 2004. The year dummies indicate an annual growth rate of $2.32 \%$ for men and $1.62 \%$ for women, which can be interpreted as the "pure time trend in real per-capita HCE", independent of demographic effects.

Robustness checks

\section{Results for n-year survival rates}

To show that our results do not depend on choosing the 5 -year survival rate instead of another $n$-year survival rate, we re-estimated the full model (3) with SR5 replaced by different $n$-year survival rates. The results can be found in Table 4. Each row in the table contains the result for one regression with $M O R T$ and $S R n$, with $S R n$ as indicated in the first column.

All coefficients are significant at the 1\% level (except for SR2 for men and SR3 and SR10 for women, which are significant at the $5 \%$ level). Also, the coefficients of the $n$ year survival rates (and MORT) are not affected much by the choice of $n$, at least in the range between 4 and 9. Our main conclusion that HCE depend on both MORT and SR therefore does not hinge on choosing a particular $S R n$.

Table 4 Regression results for $S R n$ (with $n=2, \ldots, 10$ ) and $M O R T$

\begin{tabular}{llllll}
\hline & Men & & & \multicolumn{2}{l}{ Women } \\
\cline { 2 - 3 } \cline { 5 - 6 } & SRn & MORT & & SRn & MORT \\
\hline SR2 & $17: 63(7.93)$ & $65.66(11.86)$ & & $56.57(8.07)$ & $24.95(9.18)$ \\
SR3 & $23.61(7.19)$ & $63.72(11.47)$ & & $49.92(5.80)$ & $20: 39(9.25)$ \\
SR4 & $33.46(7.16)$ & $60.24(11.08)$ & & $45.17(4.38)$ & $25.23(8.59)$ \\
SR5 & $36.45(7.31)$ & $58.30(11.23)$ & & $42.69(3.90)$ & $26.24(7.87)$ \\
SR6 & $37.32(6.34)$ & $55.31(11.56)$ & & $41.23(3.71)$ & $27.12(7.52)$ \\
SR7 & $36.29(6.10)$ & $55.37(11.74)$ & & $40.53(3.51)$ & $27.64(7.46)$ \\
SR8 & $34.30(5.52)$ & $56.67(11.58)$ & & $39.89(3.44)$ & $26.96(7.78)$ \\
SR9 & $30.48(5.31)$ & $59.26(12.03)$ & & $39.51(3.44)$ & $25.21(8.69)$ \\
SR10 & $26.50(5.11)$ & $60.94(12.27)$ & & $38.93(3.46)$ & $23: 28(10.25)$ \\
\hline
\end{tabular}

Dependent variable: $H C E$

Standard errors in parentheses; all coefficients significant at $1 \%$ (SR2 for men and SR3 and SR10 for women significant at $5 \%$ ) 


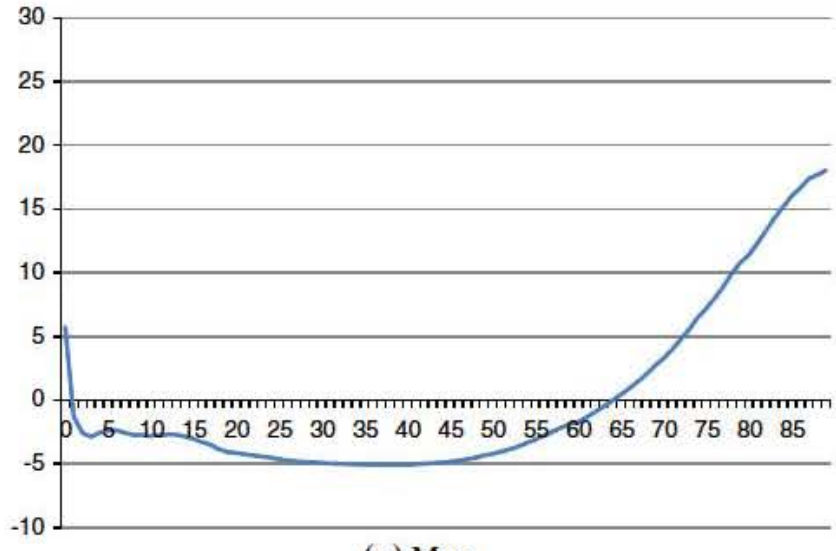

(a) Men

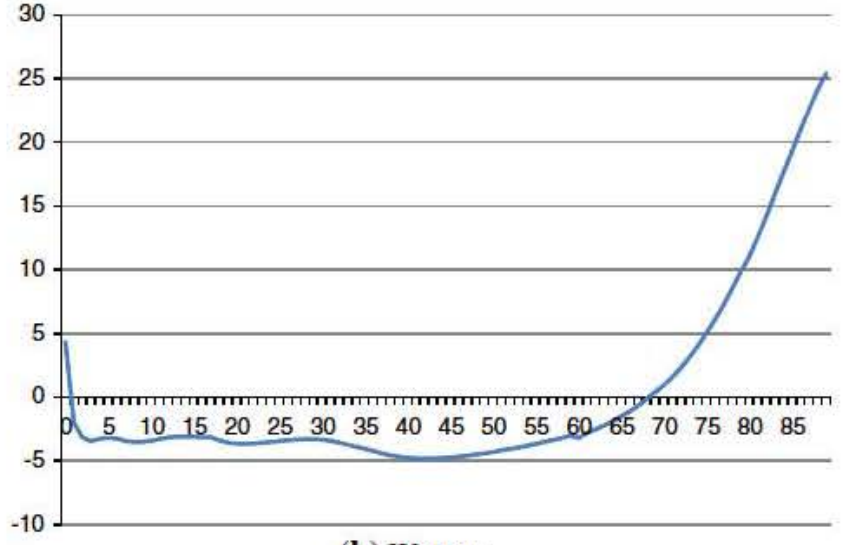

(b) Women

Fig. 1 Results for age dummy coefficients using the intrinsic estimator

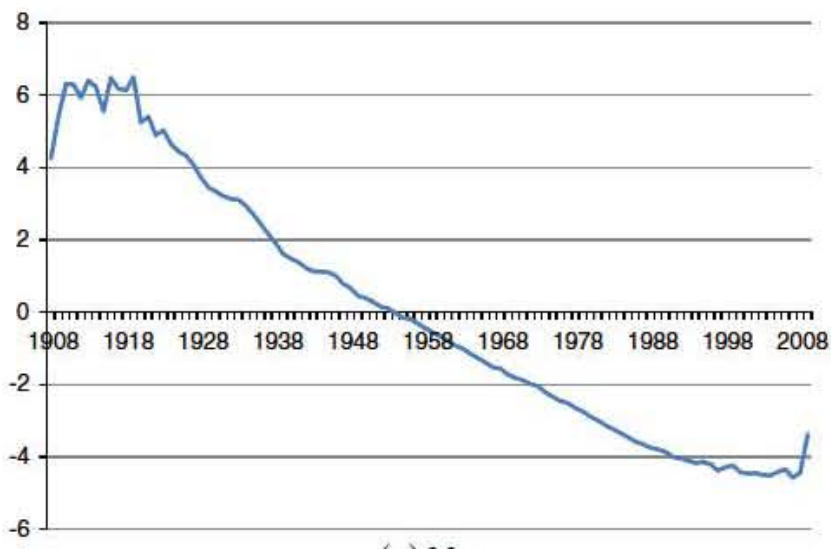

(a) Men

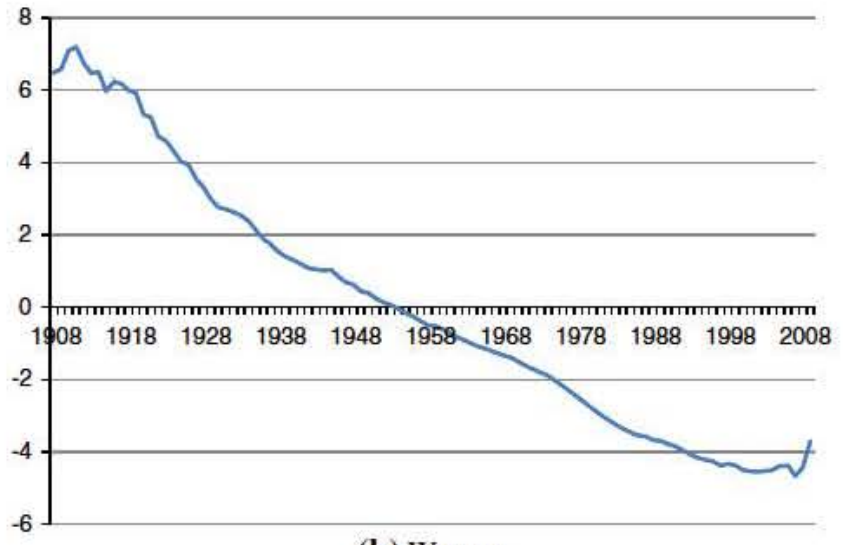

(b) Women

Fig. 2 Results for cohort dummy coefficients using the intrinsic estimator

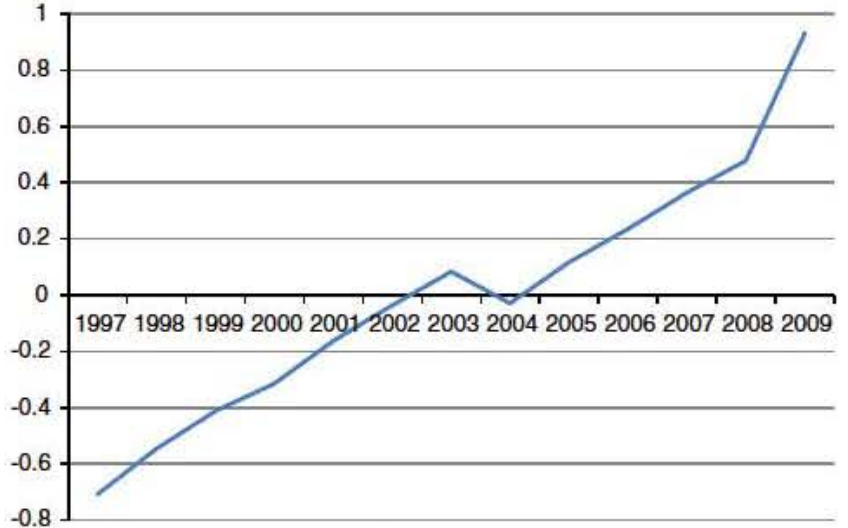

(a) Men

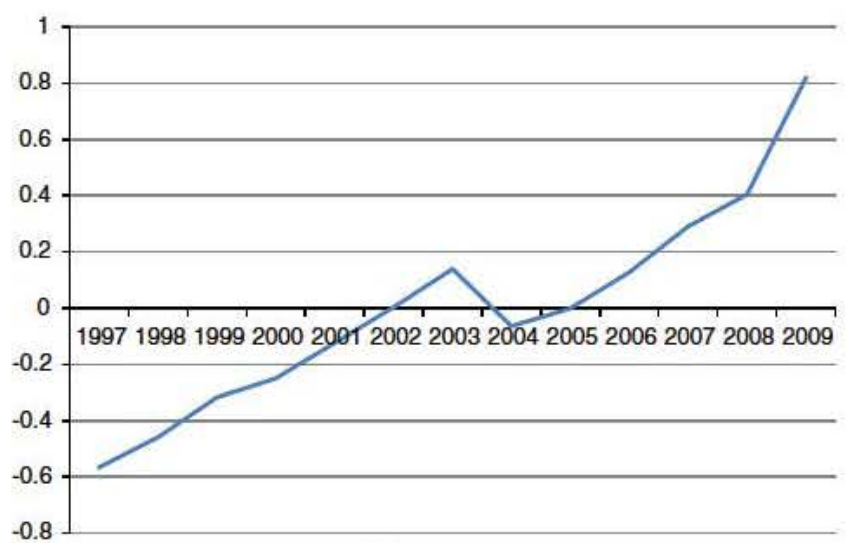

(b) Women

Fig. 3 Results for year dummy coefficients using the intrinsic estimator

Age-specific mortality effect

As explained in the fourth section, we re-estimated the full model (3) with MORT replaced by MORT interacted with 10 -year age brackets, by MORT interacted with 5-year age brackets and by MORT interacted with the age dummies $A G E_{a}$. The results can be found in Table 5.

As can be seen, the coefficient for SR5 is hardly affected by whether (and how) MORT is interacted with age. The coefficients for MORT interacted with age are often 
Table 5 Regression results for $S R 5$, for four different specifications of mortality

\begin{tabular}{|c|c|c|c|c|}
\hline & $\begin{array}{l}\text { (3) } \\
\text { MORT }\end{array}$ & $\begin{array}{l}(3 \mathrm{a}) \\
M O R T \times 10 \\
\text { year age } \\
\text { brackets }\end{array}$ & $\begin{array}{l}(3 \mathrm{~b}) \\
M O R T \times 5 \\
\text { year age } \\
\text { brackets }\end{array}$ & $\begin{array}{l}(3 \mathrm{c}) \\
M O R T \times \text { age } \\
\text { dummies }\end{array}$ \\
\hline \multicolumn{5}{|l|}{ Men } \\
\hline SR5 & $\begin{array}{l}36.45^{* * *} \\
(7.31)\end{array}$ & $\begin{array}{l}36.21 * * * \\
(7.30)\end{array}$ & $\begin{array}{l}39.99 * * * \\
(7.42)\end{array}$ & $\begin{array}{l}41.87 * * * \\
(6.95)\end{array}$ \\
\hline \multicolumn{5}{|c|}{ Women } \\
\hline SR5 & $\begin{array}{l}42.69 * * * \\
(3.90)\end{array}$ & $\begin{array}{l}43.43 * * * \\
(3.97)\end{array}$ & $\begin{array}{l}46.33 * * * \\
(3.89)\end{array}$ & $\begin{array}{l}50.96 * * * \\
(3.45)\end{array}$ \\
\hline
\end{tabular}

Dependent variable: $H C E$

Standard errors in parentheses; *** (**, *): significant at $\alpha \quad 0.01$ $(0.05,0.1)$

insignificant, and, contrary to results of previous studies, there is no noteworthy decline of the corresponding coefficients beyond age 70 .

\section{Dynamic panel models}

Table 6 contains the results for the dynamic panel model of Eq. 4. Columns (4) and (6) show the results for the difference-GMM-estimator due to Arellano and Bond [1], and column (5) and (7) the results for the system-GMM-estimator due to Blundell and Bond [3]. For comparison, we include the results of the Intrinsic Estimator in column (3).

In all the GMM estimations, $H C E_{t-1}$ and $S R 5_{t}$ are regarded to be predetermined as they do not depend on the error term in period $t$. In (4) and (5), MORT $T_{t}$ is also assumed to be predetermined, while in (6) and (7) we allow for $M O R T_{t}$ to be endogenous. To limit instrument proliferation, the number of instruments was reduced using the collapse-option of Stata's xtabond2-command [25]. Results with the full set of instruments are, however, very similar.

We first observe that the coefficients of mortality are again positive and highly significant for men although their sizes vary somewhat. For women, the coefficients are significant for the system-GMM-estimator, but become insignificant when using the difference-GMM-estimator.

Longevity, measured by the predicted value of the 5-year survival rate, remains positive and highly significant, although the size of the coefficient is generally smaller and varies considerably according to the specification. A value of 9 , which seems to be a lower bound, suggests that an increase in the 5-year survival rate by 5 percentage points raises real daily per-capita $\mathrm{HCE}$ by roughly $7 \%$.

None of the results depend on whether the mortality rate is treated as predetermined or endogenous. If anything, the
Table 6 Regression results using GMM (columns (4) to (7)) and the Intrinsic estimator (IE, column (3)), for men (upper part) and women (lower part)

\begin{tabular}{|c|c|c|c|c|c|}
\hline \multirow[b]{2}{*}{$\begin{array}{l}\text { MORT } \\
\text { endog. }\end{array}$} & \multirow{2}{*}{$\begin{array}{l}\text { IE } \\
\text { (3) }\end{array}$} & \multicolumn{4}{|l|}{ GMM } \\
\hline & & Dif. & Sys. & $\begin{array}{l}\text { Dif. } \\
\text { (6) }\end{array}$ & $\begin{array}{l}\text { Sys. } \\
\text { (7) }\end{array}$ \\
\hline \multicolumn{6}{|l|}{ Men } \\
\hline MORT & $\begin{array}{l}58.30 * * * \\
(11.23)\end{array}$ & $\begin{array}{l}70.17 * * * \\
(16.31)\end{array}$ & $\begin{array}{l}30.01 * * * \\
(5.63)\end{array}$ & $\begin{array}{l}75.56 * * * \\
(19.44)\end{array}$ & $\begin{array}{l}37.25^{* * * *} \\
(7.49)\end{array}$ \\
\hline$S R 5$ & $\begin{array}{l}36.45^{* * * *} \\
(7.31)\end{array}$ & $\begin{array}{l}34.82 * * * \\
(6.75)\end{array}$ & $\begin{array}{l}12.45^{* * * *} \\
(1.54)\end{array}$ & $\begin{array}{l}33.46 * * * \\
(7.48)\end{array}$ & $\begin{array}{l}14.23^{* * *} \\
(1.95)\end{array}$ \\
\hline$H C E_{t 1}$ & & $\begin{array}{l}0.12 * * * \\
(0.04)\end{array}$ & $\begin{array}{l}0.23^{* * *} \\
(0.06)\end{array}$ & $\begin{array}{l}0.11 * * * \\
(0.04)\end{array}$ & $\begin{array}{l}0.22 * * * \\
(0.06)\end{array}$ \\
\hline$A R(1)$ & & $(0.000)$ & $(0.000)$ & $(0.000)$ & $(0.000)$ \\
\hline$A R(2)$ & & $(0.493)$ & $(0.605)$ & $(0.484)$ & $(0.627)$ \\
\hline \multicolumn{6}{|l|}{ Women } \\
\hline MORT & $\begin{array}{l}26.24 * * * \\
(7.87)\end{array}$ & $\begin{array}{l}15.20 \\
(13.07)\end{array}$ & $\begin{array}{l}33.68 * * * \\
(8.76)\end{array}$ & $\begin{array}{l}15.25 \\
(13.12)\end{array}$ & $\begin{array}{l}41.38^{* * *} \\
(8.55)\end{array}$ \\
\hline SR5 & $\begin{array}{l}42.69 * * * \\
(3.90)\end{array}$ & $\begin{array}{l}29.01 * * * \\
(3.96)\end{array}$ & $\begin{array}{l}8.99 * * * \\
(2.51)\end{array}$ & $\begin{array}{l}28.99 * * * \\
(3.98)\end{array}$ & $\begin{array}{l}10.66^{* * *} \\
(2.22)\end{array}$ \\
\hline$H C E_{t 1}$ & & $\begin{array}{l}0.28 * * * \\
(0.03)\end{array}$ & $\begin{array}{l}0.31 * * * \\
(0.04)\end{array}$ & $\begin{array}{l}0.28 * * * \\
(0.03)\end{array}$ & $\begin{array}{l}0.28 * * * \\
(0.05)\end{array}$ \\
\hline$A R(1)$ & & $(0.000)$ & $(0.000)$ & $(0.000)$ & $(0.000)$ \\
\hline$A R(2)$ & & (0.973) & $(0.751)$ & $(0.973)$ & $(0.861)$ \\
\hline
\end{tabular}

Dependent variable: $H C E$

Standard errors in parentheses: $* * *(* *, *)$ : significant at $\alpha \quad 0.01$ $(0.05,0.1)$; for $A R(1)$ and $A R(2), p$ values in parentheses

coefficient of mortality tends to be somewhat larger when mortality is treated as endogenous.

\section{Regressions in first (and second) differences}

We finally consider the case that the variables may not be stationary. We first employ the unit root tests by Harris and Tzavalis [17] and by Im et al. [20] with and without different numbers of lags.

Table 7 shows an overview of the results; the detailed results can be found in Tables 10,11 and 12 in the "Appendix". For the dependent variable $H C E$, non-stationarity is clearly rejected. For MORT and SR5, non-stationarity in levels is never rejected, as all $p$ values are very close to 1 . For first differences, the results are ambiguous as the null hypothesis is only rejected for some of the tests. For second differences, the null is always rejected.

Therefore, in this section, we present results for the estimations in first and second differences (see Table 8). The seven models in first differences are presented in columns (11) to (17), the models in second differences in columns (21) to (27). However, for women, the AR(2)-test is highly significant (with a $p$ value $<0.001$ for the 
Table 7 Unit root tests: rejection of $H_{0}$ : non stationarity

\begin{tabular}{llllllll}
\hline & Men & & & & Women \\
& Level & $\Delta$ & $\Delta^{2}$ & & Level & $\Delta$ & $\Delta^{2}$ \\
\hline HCE & Yes & Yes & Yes & Yes & Yes & Yes \\
MORT & No & Yes/no & Yes & No & Yes/no & Yes \\
SR5 & No & Yes/no & Yes & No & Yes/no & Yes \\
\hline
\end{tabular}

difference GMM-estimator, and 0.002 for the system GMM-estimator), which is a clear indicator that the model in second differences is misspecified; therefore, we present results in second differences only for men.

The results of these estimations are similar to the ones in levels. The only noticeable difference is that for women the mortality rate is not significant when using GMM.
However, the coefficients of the 5-year survival rate remain (highly) significant and their size never falls below 11 .

\section{Summary of regression results}

We conclude that the results found in the main specification are robust to a number of changes in the specification. Altogether, the hypotheses stated in the second section are supported by the results for both sexes. Since both the mortality rate and longevity, measured by the 5-year survival rate, have a significantly positive effect on HCE, the sign of the total effect of population ageing, which leads both to a decline in mortality and an increase in longevity, is unclear. Therefore, we have to use simulation methods to determine whether the total effect will be positive, given the demographic development predicted for Germany.
Table 8 Regression results for dependent variable $\triangle H C E$ (upper and lower part) with Intrinsic estimator (IE, columns (11) (13)) and GMM (columns (14) (17)). Middle part: Dependent variable $\Delta^{2} H C E$ with IE (column (21) to (23)) and GMM (column (24) to (27))

Standard errors in parentheses:
*** (**, *): significant at
$0.01(0.05,0.1) ;$ for $A R(1)$
and $A R(2), p$ values in
parentheses

\begin{tabular}{|c|c|c|c|c|c|c|c|}
\hline \multirow[b]{2}{*}{ MORT endog. } & \multicolumn{3}{|l|}{ IE } & \multicolumn{4}{|l|}{ GMM } \\
\hline & & & & Dif. & Sys. & $\begin{array}{l}\text { Dif. } \\
\swarrow\end{array}$ & Sys. \\
\hline \multicolumn{8}{|c|}{ Men, first differences $(\Delta)$} \\
\hline & $(11)$ & $(12)$ & (13) & (14) & (15) & (16) & (17) \\
\hline \multirow[t]{2}{*}{$\triangle M O R T$} & $60.86 * * *$ & & $56.22 * * *$ & $56.54 * * *$ & $55.03 * * *$ & $83.78 * * *$ & $77.18 * * *$ \\
\hline & $(12.23)$ & & $(12.00)$ & $(11.76)$ & $(10.78)$ & $(16.71)$ & (15.16) \\
\hline \multirow[t]{2}{*}{$\Delta S R 5$} & & $20.92 * * *$ & $13.83 * *$ & $16.32 * * *$ & $15.16^{* *}$ & $12.46 * *$ & $12.08 * *$ \\
\hline & & $(6.66)$ & $(5.69)$ & $(4.97)$ & $(6.62)$ & $(5.28)$ & $(6.14)$ \\
\hline \multirow[t]{2}{*}{$\Delta H C E_{t-1}$} & & & & 0.02 & 0.01 & 0.03 & 0.02 \\
\hline & & & & $(0.03)$ & $(0.04)$ & $(0.03)$ & $(0.05)$ \\
\hline$A R(1)$ & & & & $(0.000)$ & $(0.000)$ & $(0.000)$ & $(0.000)$ \\
\hline$A R(2)$ & & & & $(0.401)$ & $(0.339)$ & $(0.312)$ & $(0.308)$ \\
\hline \multicolumn{8}{|c|}{ Men, second differences $\left(\Delta^{2}\right)$} \\
\hline & $(21)$ & $(22)$ & (23) & (24) & (25) & $(26)$ & (27) \\
\hline \multirow[t]{2}{*}{$\Delta^{2} M O R T$} & $51.28^{* * *}$ & & $42.41 * * *$ & $49.30 * * *$ & $44.72 * * *$ & $58.51 * * *$ & $64.66 * * *$ \\
\hline & $(12.20)$ & & $(10.35)$ & $(12.06)$ & $(11.08)$ & $(15.02)$ & $(14.95)$ \\
\hline \multirow[t]{2}{*}{$\Delta^{2} S R 5$} & & $29.50 * * *$ & $21.84 * * *$ & $12.36 * * *$ & $15.13 * * *$ & $11.51 * * *$ & $13.12 * * *$ \\
\hline & & $(5.66)$ & $(3.77)$ & $(4.01)$ & $(4.78)$ & $(4.01)$ & $(4.77)$ \\
\hline \multirow[t]{2}{*}{$\Delta^{2} H C E_{t-1}$} & & & & $0.32 * * *$ & $0.25^{* * *}$ & $0.32 * * *$ & $0.23 * * *$ \\
\hline & & & & $(0.04)$ & $(0.04)$ & $(0.04)$ & $(0.04)$ \\
\hline$A R(1)$ & & & & $(0.000)$ & $(0.000)$ & $(0.000)$ & $(0.000)$ \\
\hline$A R(2)$ & & & & $(0.602)$ & $(0.613)$ & $(0.970)$ & $(0.149)$ \\
\hline \multicolumn{8}{|c|}{ Women, first differences $(\Delta)$} \\
\hline & (11) & $(12)$ & (13) & (14) & (15) & (16) & (17) \\
\hline \multirow[t]{2}{*}{$\triangle M O R T$} & $33.65 * * *$ & & $20.38 *$ & 3.24 & 4.99 & 8.46 & 7.90 \\
\hline & $(8.73)$ & & $(10.53)$ & $(8.49)$ & $(7.81)$ & $(10.74)$ & $(9.07)$ \\
\hline \multirow[t]{2}{*}{$\triangle S R 5$} & & $19.22 * * *$ & $15.77 * * *$ & $19.97 * * *$ & $18.22 * * *$ & $19.43 * * *$ & $18.01 * * *$ \\
\hline & & $(3.19)$ & $(4.26)$ & $(4.33)$ & $(4.57)$ & $(4.58)$ & $(4.65)$ \\
\hline \multirow[t]{2}{*}{$\Delta H C E_{t-1}$} & & & & $0.12 * * *$ & $0.14 * * *$ & $0.11 * * *$ & $0.13 * * *$ \\
\hline & & & & $(0.03)$ & $(0.03)$ & $(0.03)$ & $(0.03)$ \\
\hline$A R(1)$ & & & & $(0.000)$ & $(0.000)$ & $(0.000)$ & $(0.000)$ \\
\hline$A R(2)$ & & & & $(0.781)$ & $(0.689)$ & $(0.791)$ & $(0.697)$ \\
\hline
\end{tabular}


Table 9 Relative values of per capita HCE when mortality rates and survival rates (and the age distribution) are set to their future values; column numbers refer to the regression results as presented in Table 3

\begin{tabular}{|c|c|c|c|c|c|c|c|c|}
\hline & \multicolumn{4}{|c|}{ Age distribution not adjusted } & \multicolumn{4}{|c|}{ Age distribution adjusted } \\
\hline & \multicolumn{2}{|l|}{ Men } & \multicolumn{2}{|c|}{ Women } & \multicolumn{2}{|l|}{ Men } & \multicolumn{2}{|c|}{ Women } \\
\hline & (1) & (3) & (1) & (3) & (1) & (3) & (1) & (3) \\
\hline MORT & レ & $\boldsymbol{\nu}$ & $\boldsymbol{\nu}$ & $\boldsymbol{\nu}$ & レ & レ & レ & $\boldsymbol{\nu}$ \\
\hline$S R 5$ & & レ & & レ & & レ & & レ \\
\hline 2009 & 1.000 & 1.000 & 1.000 & 1.000 & 1.000 & 1.000 & 1.000 & 1.000 \\
\hline 2020 & 0.975 & 1.033 & 0.991 & 1.048 & 1.078 & 1.152 & 1.058 & 1.126 \\
\hline 2030 & 0.960 & 1.061 & 0.986 & 1.084 & 1.137 & 1.286 & 1.107 & 1.237 \\
\hline 2040 & 0.948 & 1.085 & 0.982 & 1.116 & 1.184 & 1.419 & 1.160 & 1.375 \\
\hline 2050 & 0.938 & 1.107 & 0.978 & 1.145 & 1.190 & 1.505 & 1.191 & 1.487 \\
\hline 2060 & 0.929 & 1.126 & 0.974 & 1.170 & 1.184 & 1.554 & 1.192 & 1.532 \\
\hline \multicolumn{5}{|c|}{ Growth rate $(\%)$ : demographic } & 0.33 & 0.87 & 0.34 & 0.84 \\
\hline \multicolumn{5}{|c|}{ Growth rate $(\%)$ : time trend } & 1.95 & 2.32 & 1.02 & 1.62 \\
\hline
\end{tabular}

\section{Estimating the demographic effect on health care expenditures}

In the following, we do not attempt to forecast the development of health care expenditures in Germany over the coming decades. This would be a futile endeavor, because this depends to a great extent on political decisions. Instead, we are trying to measure the purely demographic impact on HCE by performing a counterfactual exercise in that we vary only the demographic factors, holding everything else constant at the 2009 level. For ease of interpretation, we divide the resulting values by the respective value of HCE in 2009, so that we can interpret the result as the relative increase of $\mathrm{HCE}$ due to the demographic change.

To facilitate comparisons with existing simulations in the literature $[4,29]$, we proceed in three steps:

- In the first step, we consider only the effect of the reduction of mortality rates (without its impact on the 5 -year survival rates and the age distribution). To do so, we calculate the age profiles of HCE and per-capita HCE that would result from changing only the mortality rates for all age groups to their values in 2020, 2030, 2040, 2050 and 2060, using the regression results of model (1) with only MORT as an additional explanatory variable besides age, year and cohort. ${ }^{20}$ These simulations can be found in the left part of Table 9 in column (1), both for men and women. ${ }^{21}$

\footnotetext{
${ }^{20}$ As we had to drop the age group $90+$ in our estimations, in all the simulations we present, we use the predicted value of HCE for the 89 year olds as the predicted value of the age group $90+$.

${ }^{21}$ The columns are numbered as in Table 3 to indicate on which regressions the simulations are based. Table 9 refers only to the regressions in levels using the Intrinsic Estimator. Simulations based on the regressions in first and second differences and on the GMM regressions can be found in Tables 13 and 14 in the "Appendix".
}

- In the second step, we take into account that, with falling mortality, the 5-year survival rates must rise, which by itself would raise HCE. We therefore calculate the age profiles of HCE and per capita HCE that would result from changing both the mortality rates and the 5-year survival rates to their values in 2020, $2030, \ldots$ 2060, using the regression results of model (3) with both MORT and SR5; see column (3) in the left part of Table 9 (both for men and women).

- In the third step, we also set the age distribution to their levels in 2020 through 2060. These results must be interpreted with caution because when we make use of the age dummy coefficients, we also have to decide how to treat the coefficients of the cohort dummies. However, there is no natural way to extrapolate the cohort effects because it is not known how healthy or unhealthy future cohorts will be. To make matters worse, there is no monotone trend in the cohort coefficients which could easily be extrapolated (see Fig. 2). We therefore did not use any predicted values for the cohorts but left them at their 2009 values, but this is not much more than the application of the Principle of Insufficient Reason. We nevertheless present these results so that they can be compared to other studies where the cohort effect is also ignored. The results of this exercise can be found in the right part of Table 9.

We first present the simulation results using the regression results of our main specification; we use the regression results of our robustness checks in the following section.

Simulation results for the main specification

The results of step 1 show that the well-known cost-ofdying effect is also present in our data. When the mortality 
rates decline in the way predicted for the coming decades and everything else stays the same, the age profiles of HCE shift downwards because, in each age bracket, fewer people are in their last year of life, so that per capita HCE decrease. However, the overall impact is rather modest: with the mortality rates of 2060, expenditures in 2009 for men would have been lower by $7.1 \%$ and those for women by $2.6 \%$ (see columns (1) for men and women).

Adding the development of the 5-year survival rates in step 2 shows that for men the total change in HCE resulting from this variation is positive and amounts to $12.6 \%$ (column (3)). For women, the respective value is $17 \%$. Thus, we see that the decline in HCE due to lower mortality rates is more than compensated by considering the concomitant increase in the 5-year survival rates of older population groups. $^{22}$

The results from step 3 show that with the 2060 age composition (along with the 2060 mortality and survival rates), health care expenditures in 2009 would have been higher by $55 \%$ for men and by $53 \%$ for women, an effect that is considerably larger than the impact of mortality and survival rates alone. The second line from the bottom in Table 9 contains the results of converting the respective increases into annual growth rates, which can be interpreted as "growth in real HCE due to demographic change". Considering changes in mortality, 5-year survival rates and the age composition, these annual growth rates are $0.87 \%$ for men and $0.84 \%$ for women.

In the last line of Table 9, we present the pure time trend in real per-capita HCE, independent of demographic effects, calculated from the coefficients for the year dummies. It can be assumed that this trend is to a large extent due to medical progress. The annual growth rates for the full model are $2.32 \%$ for men and $1.62 \%$ for women and are thus considerably larger than the purely demographic effect estimated above. If these two effects are added up, the resulting total growth rates are around $3.2 \%$ for men and $2.5 \%$ for women, which is somewhat higher than common forecasts of the growth rate of real per capita income in the ageing German population. Thus, they suggest that demographic change and technical progress combined may after all present problems for the financing of health care in Germany.

\section{Robustness check}

For all the estimations we performed as robustness checks, we also determined the corresponding simulations in the same way as for the main specification. These results can be found

\footnotetext{
${ }^{22}$ We emphasize again that these results do not at all depend on how the problem of linear dependence between age, period and cohort is solved.
}

in Tables 13 and 14 in the "Appendix". The resulting annual demographic growth rates based on the full model are slightly smaller than the ones reported above and lie between 0.47 and $0.79 \%$ for men and between 0.44 and $0.72 \%$ for women. Adding the time trend, total annual growth rates lie in the range of $2.53 .05 \%$ for men and in the range of $1.62 .2 \%$ for women.

\section{Conclusions and caveats}

In this paper, we have used a pseudo-panel of health care expenditure data for Germany to demonstrate that percapita HCE are significantly influenced by the age composition of the population, mortality rates and the development of longevity, as measured by the age-specific 5-year survival rates. We believe that the last effect, which is quite substantial, mirrors the medical profession's willingness to perform expensive or risky treatments on elderly patients, and the patients' willingness to undergo these treatments, if the patients can be expected to live long enough to enjoy the benefits of the treatment.

The results of the simulations based on the regression coefficients show that, if past trends continue, per-capita HCE would rise by more than $1 \%$ per year for women and more than $2 \%$ per year for men even without demographic change. Moreover, while we can confirm that simulations on the basis of the population age structure alone are misleading, the same applies when only age-specific mortality rates are added. The effect of rising longevity cannot be ignored, either. One way to take this into account is to include a measure of age-specific 5-year survival rates. In sum, the (negative) effect of falling mortality rates on health care expenditures is more than compensated by the (positive) effect of increasing 5-year survival rates. Adding the effect of a changing age composition in the population, the total effect of demographic change on per capita HCE is estimated to amount to an annual growth rate of about $0.85 \%$.

The type of data employed for this study has important advantages, but also certain drawbacks. To our knowledge, this is the first attempt to quantify the effect of rising longevity on the development of age-specific health care expenditures over time. However, since we used age and sex group averages instead of individual expenditure data, the well-known cost-of-dying effect on HCE is accounted for only in an indirect form: by estimating the impact of the mortality rate within a population group on average expenditures.

It can further be argued that mortality and survival rates themselves are influenced by HCE and therefore endogenous. With respect to $S R 5$, the endogeneity does not occur as we used its predicted value instead of SR5 itself. For $M O R T$, possible endogeneity is accounted for in two of the 
four dynamic panel models (estimated by GMM), which had basically no effect on the regression results. This seems reasonable as one may argue that, unlike in individual data, for group averages the causal effect of HCE on mortality should not be too strong. It does not seem likely that the correlation between the variation in $\mathrm{HCE}$ and MORT is caused primarily by the fact that tight rationing for a particular age sex group as a whole within a certain year by all physicians leads to a higher mortality rate, but rather by a higher mortality rate of an age-sex group causing higher expenditures.

We sum up by stating the main purpose of this paper, namely to examine whether ageing i.e. an increase of longevity alongside a fall in mortality rates as such will increase health expenditures, and the answer to this question is a clear "yes". Independently from the specification used, the 5-year survival rate always has a positive and sizeable impact on health care expenditures so that for Germany a "Eubie Blake effect" indeed exists.

Acknowledgments We are grateful to the Bundesversicherungsamt, Bonn, for the provision of the health care expenditure dataset, to the Statistische Bundesamt, Wiesbaden, for the provision of the demo graphic data, and to an anonymous referee for helpful suggestions. Valuable comments by James Binfield, Ralf Brüggemann, Terkel Christiansen, Victor R. Fuchs, Martin Karlsson, Florian Klohn, Winfried Pohlmeier, Niklas Potrafke, Esther Schuch and Volker Ul rich are gratefully acknowledged.

\section{Appendix}

The following Tables 10, 11 and 12 provide the unit root tests for the variables HCE, MORT and SR5.

Tables 13 and 14 present the simulation results for the regressions of the robustness checks.

Table 10 Unit root tests, dep. variable: daily HCE

\begin{tabular}{|c|c|c|c|c|c|c|c|c|c|c|}
\hline \multirow{3}{*}{ Time trend } & \multirow{2}{*}{\multicolumn{2}{|c|}{$\frac{H C E}{\text { Yes }}$}} & \multirow{2}{*}{\multicolumn{2}{|c|}{$\frac{\Delta H C E}{\text { No }}$}} & \multirow{2}{*}{\multicolumn{2}{|c|}{$\frac{\Delta H C E}{\text { Yes }}$}} & \multirow{2}{*}{\multicolumn{2}{|c|}{$\frac{\Delta^{2} H C E}{\text { No }}$}} & \multirow{2}{*}{\multicolumn{2}{|c|}{$\frac{\Delta^{2} H C E}{\text { Yes }}$}} \\
\hline & & & & & & & & & & \\
\hline & Stat. & $p$ value & Stat. & $p$ value & Stat. & $p$ value & Stat. & $p$ value & Stat. & $p$ value \\
\hline \multicolumn{11}{|l|}{ Men } \\
\hline Harris Tsavalis $t$ & 0.316 & 0.000 & 0.202 & 0.000 & 0.486 & 0.951 & 0.124 & 0.000 & 0.093 & 0.000 \\
\hline Im Pesaran Shin $W_{t}$ & 2.582 & $<0.01$ & 3.507 & $<0.01$ & 3.679 & $<0.01$ & 4.844 & $<0.01$ & 4.756 & $<0.01$ \\
\hline Im Pesaran Shin $W_{t}$ (lag up to 1 ) & 1.356 & 0.088 & 16.022 & 0.000 & 10.518 & 0.000 & 27.355 & 0.000 & 18.079 & 0.000 \\
\hline Im Pesaran Shin $W_{t}$ (lag up to 2) & 1.745 & 0.041 & 15.666 & 0.000 & 9.788 & 0.000 & 25.103 & 0.000 & 17.280 & 0.000 \\
\hline Im Pesaran Shin $W_{t}$ (lag up to 3 ) & 1.339 & 0.090 & 11.258 & 0.000 & 5.678 & 0.000 & 17.004 & 0.000 & 9.909 & 0.000 \\
\hline Im Pesaran Shin $W_{t}$ (lag up to 4 ) & 44.188 & 0.000 & 38.012 & 0.000 & 2.502 & 0.006 & 12.344 & 0.000 & 9.652 & 0.000 \\
\hline \multicolumn{11}{|l|}{ Women } \\
\hline Harris Tsavalis $t$ & 0.355 & 0.001 & 0.188 & 0.000 & 0.404 & 0.308 & 0.159 & 0.000 & 0.125 & 0.000 \\
\hline Im Pesaran Shin $W_{t}$ & 2.958 & $<0.01$ & 3.657 & $<0.01$ & 4.027 & $<0.01$ & 5.192 & $<0.01$ & 5.018 & $<0.01$ \\
\hline Im Pesaran Shin $W_{t}$ (lag up to 1 ) & 5.460 & 0.000 & 16.221 & 0.000 & 14.615 & 0.000 & 29.605 & 0.000 & 19.986 & 0.000 \\
\hline Im Pesaran Shin $W_{t}$ (lag up to 2) & 7.541 & 0.000 & 15.188 & 0.000 & 10.013 & 0.000 & 21.788 & 0.000 & 13.408 & 0.000 \\
\hline Im Pesaran Shin $W_{t}$ (lag up to 3 ) & 3.702 & 0.000 & 11.984 & 0.000 & 2.270 & 0.012 & 14.892 & 0.000 & 66.537 & 0.000 \\
\hline Im Pesaran Shin $W_{t}$ (lag up to 4$)$ & 36.543 & 0.000 & 45.483 & 0.000 & 1.461 & 0.072 & 12.543 & 0.000 & 10.228 & 0.000 \\
\hline
\end{tabular}

IPS test with lags contains optimal number of lags (up to the maximal number of lags given in parenthesis) according to BIC 
Table 11 Unit root tests, dep. variable: $M O R T$

\begin{tabular}{|c|c|c|c|c|c|c|c|c|c|c|}
\hline \multirow{3}{*}{ Time trend } & \multirow{2}{*}{\multicolumn{2}{|c|}{$\begin{array}{l}\text { MORT } \\
\text { Yes }\end{array}$}} & \multirow{2}{*}{\multicolumn{2}{|c|}{$\frac{\Delta M O R T}{\text { No }}$}} & \multirow{2}{*}{\multicolumn{2}{|c|}{$\frac{\Delta M O R T}{\mathrm{Yes}}$}} & \multirow{2}{*}{\multicolumn{2}{|c|}{$\frac{\Delta^{2} M O R T}{\text { No }}$}} & \multirow{2}{*}{\multicolumn{2}{|c|}{$\frac{\Delta^{2} M O R T}{\text { Yes }}$}} \\
\hline & & & & & & & & & & \\
\hline & Stat. & $p$ value & Stat. & $p$ value & Stat. & $p$ value & Stat. & $p$ value & Stat. & $p$ value \\
\hline \multicolumn{11}{|l|}{ Men } \\
\hline Harris Tsavalis $t$ & 1.062 & 1.000 & 0.378 & 0.000 & 0.987 & 1.000 & 0.782 & 0.000 & 0.702 & 0.000 \\
\hline Im Pesaran Shin $W_{t}$ & 0.477 & $>0.10$ & 1.538 & $>0.10$ & 3.924 & $<0.01$ & 6.493 & $<0.01$ & 6.516 & $<0.01$ \\
\hline Im Pesaran Shin $W_{t}$ (lag up to 1$)$ & 26.843 & 1.000 & 9.075 & 1.000 & 15.452 & 0.000 & 42.604 & 0.000 & 31.978 & 0.000 \\
\hline Im Pesaran Shin $W_{t}$ (lag up to 2) & 28.353 & 1.000 & 12.626 & 1.000 & 13.437 & 0.000 & 39.433 & 0.000 & 30.945 & 0.000 \\
\hline Im Pesaran Shin $W_{t}$ (lag up to 3 ) & 28.149 & 1.000 & 12.995 & 1.000 & 10.137 & 0.000 & 35.249 & 0.000 & 25.113 & 0.000 \\
\hline Im Pesaran Shin $W_{t}$ (lag up to 4 ) & 25.275 & 1.000 & 17.103 & 1.000 & 9.912 & 0.000 & 34.699 & 0.000 & 4.021 & 0.000 \\
\hline \multicolumn{11}{|l|}{ Women } \\
\hline Harris Tsavalis $t$ & 1.144 & 1.000 & 0.793 & 0.934 & 1.072 & 1.000 & 0.600 & 0.000 & 0.390 & 0.000 \\
\hline Im Pesaran Shin $W_{t}$ & 1.327 & $>0.10$ & 0.740 & $>0.10$ & 2.983 & $<0.01$ & 5.045 & $<0.01$ & 5.273 & $<0.01$ \\
\hline Im Pesaran Shin $W_{t}$ (lag up to 1 ) & 31.784 & 1.000 & 13.085 & 1.000 & 6.146 & 0.000 & 26.354 & 0.000 & 18.345 & 0.000 \\
\hline Im Pesaran Shin $W_{t}$ (lag up to 2) & 32.618 & 1.000 & 19.735 & 1.000 & 2.449 & 0.007 & 22.604 & 0.000 & 16.391 & 0.000 \\
\hline Im Pesaran Shin $W_{t}$ (lag up to 3 ) & 31.344 & 1.000 & 19.887 & 1.000 & 2.364 & 0.009 & 21.566 & 0.000 & 14.311 & 0.000 \\
\hline Im Pesaran Shin $W_{t}$ (lag up to 4 ) & 26.890 & 1.000 & 20.684 & 1.000 & 1.079 & 0.140 & 18.747 & 0.000 & 3.986 & 0.000 \\
\hline
\end{tabular}

IPS test with lags contains optimal number of lags (up to the maximal number of lags given in parentheses) according to BIC

Table 12 Unit root tests, dep. variable: daily SR5

\begin{tabular}{|c|c|c|c|c|c|c|c|c|c|c|}
\hline \multirow{3}{*}{ Time trend } & \multirow{2}{*}{\multicolumn{2}{|c|}{$\frac{\text { SR5 }}{\text { Yes }}$}} & \multirow{2}{*}{\multicolumn{2}{|c|}{$\frac{\Delta S R 5}{\text { No }}$}} & \multirow{2}{*}{\multicolumn{2}{|c|}{$\frac{\Delta S R 5}{\text { Yes }}$}} & \multirow{2}{*}{\multicolumn{2}{|c|}{$\frac{\Delta^{2} S R 5}{\mathrm{No}}$}} & \multirow{2}{*}{\multicolumn{2}{|c|}{$\frac{\Delta^{2} S R 5}{\mathrm{Yes}}$}} \\
\hline & & & & & & & & & & \\
\hline & Stat. & $p$ value & Stat. & $p$ value & Stat. & $p$ value & Stat. & $p$ value & Stat. & $p$ value \\
\hline \multicolumn{11}{|l|}{ Men } \\
\hline Harris Tsavalis $t$ & 0.943 & 1.000 & 0.617 & 0.000 & 1.0488 & 1.000 & 0.480 & 0.000 & 0.395 & 0.000 \\
\hline Im Pesaran Shin $W_{t}$ & 0.205 & $>0.10$ & 0.899 & $>0.10$ & 3.170 & $<0.01$ & 4.052 & $<0.01$ & 3.856 & $<0.01$ \\
\hline Im Pesaran Shin $W_{t}$ (lag up to 1 ) & 17.368 & 1.000 & 5.993 & 1.000 & 8.429 & 0.000 & 19.511 & 0.000 & 10.829 & 0.000 \\
\hline Im Pesaran Shin $W_{t}$ (lag up to 2 ) & 17.077 & 1.000 & 6.240 & 1.000 & 7.698 & 0.000 & 18.645 & 0.000 & 9.074 & 0.000 \\
\hline Im Pesaran Shin $W_{t}$ (lag up to 3 ) & 15.217 & 1.000 & 5.904 & 1.000 & 5.477 & 0.000 & 13.483 & 0.000 & 10.088 & 0.000 \\
\hline Im Pesaran Shin $W_{t}$ (lag up to 4 ) & 0.987 & 0.838 & 1.915 & 0.972 & 5.940 & 0.000 & 13.653 & 0.000 & 9.422 & 0.000 \\
\hline \multicolumn{11}{|l|}{ Women } \\
\hline Harris Tsavalis $t$ & 0.981 & 1.000 & 0.897 & 1.000 & 1.086 & 1.000 & 0.519 & 0.000 & 0.264 & 0.000 \\
\hline Im Pesaran Shin $W_{t}$ & 0.211 & $>0.10$ & 0.187 & $>0.10$ & 3.065 & $<0.01$ & 3.704 & $<0.01$ & 3.579 & $<0.01$ \\
\hline Im Pesaran Shin $W_{t}$ (lag up to 1$)$ & 20.869 & 1.000 & 11.922 & 1.000 & 7.553 & 0.000 & 16.465 & 0.000 & 8.743 & 0.000 \\
\hline Im Pesaran Shin $W_{t}$ (lag up to 2) & 20.519 & 1.000 & 11.333 & 1.000 & 7.368 & 0.000 & 16.040 & 0.000 & 7.970 & 0.000 \\
\hline Im Pesaran Shin $W_{t}$ (lag up to 3 ) & 18.807 & 1.000 & 11.074 & 1.000 & 8.300 & 0.000 & 11.062 & 0.000 & 3.903 & 0.000 \\
\hline Im Pesaran Shin $W_{t}$ (lag up to 4 ) & 11.269 & 1.000 & 9.930 & 1.000 & 8.413 & 0.000 & 11.404 & 0.000 & 8.151 & 0.000 \\
\hline
\end{tabular}

IPS test with lags contains optimal number of lags (up to the maximal number of lags given in parentheses) according to BIC 
Table 13 Relative values of per capita HCE when mortality rates and survival rates (and the age distribution) are set to their future values

\begin{tabular}{|c|c|c|c|c|c|c|c|c|c|c|c|c|c|c|c|}
\hline \multicolumn{16}{|c|}{ Men } \\
\hline \multicolumn{4}{|l|}{ IE } & \multicolumn{12}{|l|}{ GMM } \\
\hline (11) & (13) & (21) & (23) & (4) & (5) & (6) & (7) & (14) & (15) & (16) & (17) & (24) & (25) & (26) & (27) \\
\hline \multirow[t]{2}{*}{$\Delta$} & $\Delta^{2}$ & $\Delta$ & $\Delta^{2}$ & Level & Level & Level & Level & $\Delta$ & $\Delta$ & $\Delta$ & $\Delta$ & $\Delta^{2}$ & $\Delta^{2}$ & $\Delta^{2}$ & $\Delta^{2}$ \\
\hline & & & & Dif. & Sys. & $\begin{array}{l}\text { Dif. } \\
レ\end{array}$ & Sys. & Dif. & Sys. & Dif. & Sys. & Dif. & Sys. & Dif. & Sys. \\
\hline \multirow[t]{3}{*}{ 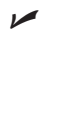 } & $\nu$ & 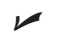 & 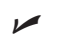 & $\checkmark$ & 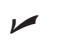 & 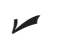 & $\checkmark$ & 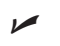 & $\swarrow$ & $\swarrow$ & $\swarrow$ & 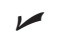 & 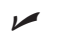 & $\swarrow$ & 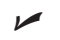 \\
\hline & & $\nu$ & 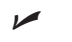 & $\nu$ & $\nu$ & $\swarrow$ & レ & レ & $v$ & $\nu$ & 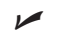 & V & レ & 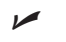 & 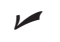 \\
\hline & & & & $\nu$ & $v$ & $\nu$ & $\nu$ & $\nu$ & $\nu$ & $v$ & $\nu$ & $v$ & $\nu$ & $\nu$ & $\nu$ \\
\hline
\end{tabular}

$H C E_{t-1}$

Age distribution not adjusted

\begin{tabular}{|c|c|c|c|c|c|c|c|c|c|c|c|c|c|c|c|c|}
\hline 2009 & 1.000 & 1.000 & 1.000 & 1.000 & 1.000 & 1.000 & 1.000 & 1.000 & 1.000 & 1.000 & 1.000 & 1.000 & 1.000 & 1.000 & 1.000 & 1.000 \\
\hline 2020 & 0.978 & 0.981 & 1.000 & 1.017 & 1.026 & 1.007 & 1.022 & 1.007 & 1.004 & 1.002 & 0.988 & 0.990 & 1.000 & 1.006 & 0.996 & 0.996 \\
\hline 2030 & 0.964 & 0.970 & 1.003 & 1.033 & 1.050 & 1.015 & 1.044 & 1.016 & 1.010 & 1.008 & 0.984 & 0.987 & 1.004 & 1.014 & 0.996 & 0.997 \\
\hline 2040 & 0.954 & 0.961 & 1.007 & 1.046 & 1.071 & 1.022 & 1.062 & 1.022 & 1.015 & 1.012 & 0.981 & 0.984 & 1.007 & 1.020 & 0.997 & 0.998 \\
\hline 2050 & 0.944 & 0.953 & 1.010 & 1.057 & 1.089 & 1.027 & 1.078 & 1.029 & 1.020 & 1.016 & 0.978 & 0.983 & 1.009 & 1.026 & 0.997 & 0.999 \\
\hline 2060 & 0.936 & 0.946 & 1.012 & 1.068 & 1.105 & 1.033 & 1.093 & 1.034 & 1.025 & 1.020 & 0.977 & 0.981 & 1.012 & 1.031 & 0.998 & 1.000 \\
\hline \multicolumn{17}{|c|}{ Age distribution adjusted } \\
\hline 2009 & 1.000 & 1.000 & 1.000 & 1.000 & 1.000 & 1.000 & 1.000 & 1.000 & 1.000 & 1.000 & 1.000 & 1.000 & 1.000 & 1.000 & 1.000 & 1.000 \\
\hline 2020 & 1.081 & 1.085 & 1.110 & 1.131 & 1.144 & 1.119 & 1.139 & 1.119 & 1.114 & 1.113 & 1.095 & 1.097 & 1.110 & 1.117 & 1.104 & 1.104 \\
\hline 2030 & 1.143 & 1.151 & 1.201 & 1.243 & 1.270 & 1.217 & 1.260 & 1.218 & 1.210 & 1.207 & 1.173 & 1.177 & 1.201 & 1.215 & 1.190 & 1.191 \\
\hline 2040 & 1.193 & 1.206 & 1.284 & 1.351 & 1.393 & 1.310 & 1.378 & 1.311 & 1.299 & 1.294 & 1.240 & 1.246 & 1.284 & 1.307 & 1.267 & 1.269 \\
\hline 2050 & 1.203 & 1.220 & 1.324 & 1.414 & 1.471 & 1.359 & 1.450 & 1.361 & 1.344 & 1.337 & 1.264 & 1.273 & 1.325 & 1.355 & 1.301 & 1.304 \\
\hline 2060 & 1.199 & 1.218 & 1.341 & 1.446 & 1.514 & 1.380 & 1.491 & 1.383 & 1.364 & 1.356 & 1.273 & 1.282 & 1.341 & 1.376 & 1.314 & 1.317 \\
\hline $\begin{array}{l}\% \text { growth rate } \\
\text { demographic }\end{array}$ & 0.36 & 0.39 & 0.58 & 0.73 & 0.82 & 0.63 & 0.79 & 0.64 & 0.61 & 0.60 & 0.47 & 0.49 & 0.58 & 0.63 & 0.54 & 0.54 \\
\hline $\begin{array}{l}\% \text { growth rate } \\
\text { time trend }\end{array}$ & 1.96 & 1.98 & 2.10 & 2.20 & 2.28 & 2.13 & 2.26 & 2.14 & 2.13 & 2.12 & 2.05 & 2.06 & 2.10 & 2.13 & 2.08 & 2.08 \\
\hline
\end{tabular}

Table 14 Relative values of per capita HCE when mortality rates and survival rates (and the age distribution) are set to their future values

\begin{tabular}{|c|c|c|c|c|c|c|c|c|c|c|}
\hline \multirow[b]{3}{*}{ MORT endog. } & \multicolumn{10}{|c|}{ Women } \\
\hline & \multicolumn{2}{|l|}{ IE } & \multicolumn{8}{|l|}{ GMM } \\
\hline & $\begin{array}{l}(11) \\
\Delta\end{array}$ & $\begin{array}{l}(13) \\
\Delta\end{array}$ & $\begin{array}{l}\text { (4) } \\
\text { Level } \\
\text { Dif. }\end{array}$ & $\begin{array}{l}\text { (5) } \\
\text { Level } \\
\text { Sys. }\end{array}$ & $\begin{array}{l}(6) \\
\text { Level } \\
\text { Dif. } \\
\swarrow\end{array}$ & $\begin{array}{l}\text { (7) } \\
\text { Level } \\
\text { Sys. } \\
\end{array}$ & $\begin{array}{l}(14) \\
\Delta \\
\text { Dif. }\end{array}$ & $\begin{array}{l}(15) \\
\Delta \\
\text { Sys. }\end{array}$ & $\begin{array}{l}(16) \\
\Delta \\
\text { Dif. } \\
\swarrow\end{array}$ & $\begin{array}{l}(17) \\
\Delta \\
\text { Sys. } \\
\nu\end{array}$ \\
\hline$M O R T$ & レ & レ & レ & $\nu$ & レ & $\boldsymbol{}$ & レ & $\nu$ & レ & レ \\
\hline$S R 5$ & & レ & レ & レ & $\swarrow$ & $\swarrow$ & レ & レ & $レ$ & $\swarrow$ \\
\hline$H C E_{t-1}$ & & & レ & レ & レ & $\boldsymbol{V}$ & レ & レ & レ & レ \\
\hline \multicolumn{11}{|c|}{ Age distribution not adjusted } \\
\hline 2009 & 1.000 & 1.000 & 1.000 & 1.000 & 1.000 & 1.000 & 1.000 & 1.000 & 1.000 & 1.000 \\
\hline 2020 & 0.989 & 1.014 & 1.033 & 1.001 & 1.033 & 1.001 & 1.025 & 1.023 & 1.023 & 1.021 \\
\hline 2030 & 0.983 & 1.026 & 1.059 & 1.003 & 1.059 & 1.003 & 1.044 & 1.039 & 1.040 & 1.037 \\
\hline 2040 & 0.977 & 1.036 & 1.081 & 1.006 & 1.081 & 1.006 & 1.061 & 1.054 & 1.056 & 1.051 \\
\hline 2050 & 0.972 & 1.045 & 1.101 & 1.008 & 1.101 & 1.008 & 1.076 & 1.067 & 1.069 & 1.064 \\
\hline 2060 & 0.968 & 1.053 & 1.119 & 1.010 & 1.118 & 1.010 & 1.089 & 1.079 & 1.081 & 1.075 \\
\hline
\end{tabular}


Table 14 continued

\begin{tabular}{|c|c|c|c|c|c|c|c|c|c|c|}
\hline \multirow[b]{3}{*}{ MORT endog. } & \multicolumn{10}{|c|}{ Women } \\
\hline & \multicolumn{2}{|l|}{ IE } & \multicolumn{8}{|l|}{ GMM } \\
\hline & $\begin{array}{l}(11) \\
\Delta\end{array}$ & $\begin{array}{l}(13) \\
\Delta\end{array}$ & $\begin{array}{l}\text { (4) } \\
\text { Level } \\
\text { Dif. }\end{array}$ & $\begin{array}{l}(5) \\
\text { Level } \\
\text { Sys. }\end{array}$ & $\begin{array}{l}(6) \\
\text { Level } \\
\text { Dif. } \\
\boldsymbol{}\end{array}$ & $\begin{array}{l}(7) \\
\text { Level } \\
\text { Sys. } \\
\end{array}$ & $\begin{array}{l}(14) \\
\Delta \\
\text { Dif. }\end{array}$ & $\begin{array}{l}(15) \\
\Delta \\
\text { Sys. }\end{array}$ & $\begin{array}{l}(16) \\
\Delta \\
\text { Dif. } \\
\swarrow\end{array}$ & $\begin{array}{l}(17) \\
\Delta \\
\text { Sys. } \\
\swarrow\end{array}$ \\
\hline \multicolumn{11}{|l|}{ Age distribution adjusted } \\
\hline 2009 & 1.000 & 1.000 & 1.000 & 1.000 & 1.000 & 1.000 & 1.000 & 1.000 & 1.000 & 1.000 \\
\hline 2020 & 1.056 & 1.085 & 1.108 & 1.070 & 1.108 & 1.070 & 1.097 & 1.094 & 1.095 & 1.093 \\
\hline 2030 & 1.103 & 1.159 & 1.202 & 1.130 & 1.202 & 1.131 & 1.181 & 1.175 & 1.176 & 1.172 \\
\hline 2040 & 1.154 & 1.246 & 1.317 & 1.199 & 1.317 & 1.200 & 1.284 & 1.273 & 1.276 & 1.269 \\
\hline 2050 & 1.183 & 1.310 & 1.408 & 1.245 & 1.408 & 1.246 & 1.361 & 1.347 & 1.351 & 1.342 \\
\hline 2060 & 1.182 & 1.327 & 1.440 & 1.254 & 1.440 & 1.256 & 1.385 & 1.369 & 1.374 & 1.363 \\
\hline$\%$ growth rate demographic & 0.33 & 0.56 & 0.72 & 0.44 & 0.72 & 0.45 & 0.64 & 0.62 & 0.62 & 0.61 \\
\hline$\%$ growth rate time trend & 1.01 & 1.26 & 1.46 & 1.14 & 1.46 & 1.14 & 1.36 & 1.33 & 1.34 & 1.32 \\
\hline
\end{tabular}

\section{References}

1. Arellano, M., Bond, S.: Some tests of specification for panel data: Monte Carlo evidence and an application to employment equa tions. Rev. Econ. Stud. 58(2), 277297 (1991)

2. Bech, M., Christiansen, T., Khoman, E., Lauridsen, J., Weale, M.: Ageing and health care expenditure in EU 15. Eur. J. Health Econ. 12(5), 469478 (2011)

3. Blundell, R., Bond, S.: Initial conditions and moment restrictions in dynamic panel data models. J. Econom. 87(1), 115143 (1998)

4. Breyer, F., Felder, S.: Life expectancy and health care expendi ture: A new calculation for Germany using the costs of dying. Health Policy 75(2), 178186 (2006)

5. Breyer, F., Hupfeld, S.: Fairness of public pensions and old age poverty. FinanzArchiv 65, 358380 (2009)

6. Callahan, D.: Setting Limits: Medical Goals in an Aging Society. New York (1987)

7. Colombier, C., Weber, W.: Projecting health care expenditure for Switzerland: further evidence against the 'red herring' hypothe sis. Int. J. Health Plan. Manag. 26(3), 246263 (2011)

8. Crimmins, E.M., Saito, Y., Ingegneri, D.: Trends in disability free life expectancy in the United States, 1970 90. Popul. Dev. Rev. 23(3), 555572 (1997)

9. Daniels, N.: Just Health Care. Cambridge University Press, Cambridge (1985)

10. Davidson, R., MacKinnon, J.G.: Estimation and Inference in Econometrics. New York (1993)

11. Deaton, A.: Panel data from time series of cross sections. J. Econom. 30(1 2), 109126 (1985)

12. Fang, H., Keane, M., Khwaja, A., Salm, M., Silverman, D.: Testing the mechanisms of structural models: The case of the Mickey mantle effect. Am. Econ. Rev. Papers Proc. 97(2), 5359 (2007)

13. Felder, S., Werblow, A., Zweifel, P.: Do red herrings swim in circles? Controlling for the endogeneity of time to death. J. Health Econ. 29(2), 205212 (2010)

14. Fuchs, V.: Though much is taken: Reflections on aging, health and medical care. Milbank Mem. Fund Q. Health Soc. 62(2), 143166 (1984)

15. Hagist, C., Klusen, N., Plate, A., Raffelhüschen, B.: Social Health Insurance the Major Driver of Unsustainable Fiscal Policy?, CESifo Working Paper; No. 1574 (2005)
16. Hagist, C., Kotlikoff, L.: Who's Going Broke? Comparing Growth in Healthcare costs in ten OECD Countries, NBER Working Paper; w11833 (2005)

17. Harris, R, Tzavalis, E.: Inference for unit roots in dynamic panels where the time dimension is fixed. J.Econom. 91(2), 201226 (1999)

18. Human Mortality Database: University of California, Berkeley (USA), and Max Planck Institute for Demographic Research (Germany). Available at http://www.mortality.org or http://www. humanmortality.de (data downloaded on May 31, 2011) (2011)

19. Hurst, S.A., Slowther, A. M., Forde, R., Pegoraro, R., Reiter Theil, S., Perrier, A., Garrett Mayer, E., Danis, M.: Prevalence and determinants of physician bedside rationing. Data from Europe. J. Gen. Intern. Med. 21(11), 11381143 (2006)

20. Im, K., Pesaran, M., Shin, Y.: Testing for unit roots in hetero geneous panels. J. Econom. 115, 5374 (2003)

21. Inkmann, J., Klotz, S., Pohlmeier, W.: Permanente Narben oder temporäre Blessuren? Eine Studie über die langfristigen Folgen eines missglückten Einstiegs in das Berufsleben auf der Grund lage von Pseudo Panel Daten. In: Pfeiffer, F., Pohlmeier, W. (eds) Qualifikation Weiterbildung und Arbeitsmarkterfolg, pp. 223 255. Nomos, Baden Baden (1998)

22. Karlsson, M., Klohn, F.: Testing the red herring hypothesis on an aggregated level: ageing, time to death and care costs for older people in Sweden. Eur. J. Health Econ. (forthcoming)

23. Miller, T.: Increasing longevity and medicare expenditures. Demography 38(2), 215226 (2001)

24. Riley, G.F., Lubitz, J.D.: Long term trends in medicare payments in the last year of life. Health Serv. Res. 45(2), 565576 (2010)

25. Roodman, D.: "How to Do xtabond2: An Introduction to "Dif ference" and "System" GMM in Stata," Center for Global Development Working Paper 103 (2006)

26. Seshamani, M., Gray, A.: Ageing and health care expenditure: The red herring argument revisited. Health Econ. 13, 303314 (2004)

27. Shang, B., Goldman, D.: Does age or life expectancy better predict health care expenditures?. Health Econ. 17(4), 487501 (2008)

28. Statistisches Bundesamt: 12. koordinierte Bevölkerungsvoraus berechnung. Wiesbaden (2009)

29. Stearns, S., Norton, E.: Time to include time to death? The future of health care expenditure predictions. Health Econ. 13(4), 315327 (2004) 
30. Strech, D., Synofzik, M., Marckmann, G.: How physicians allo cate scarce resources at the bedside: A systematic review of qualitative studies. J. Med. Philos. 33(1), 8099 (2008)

31. Tu, Y. K., Krämer, N., Lee, W. C.: Addressing the identification problem in age period cohort analysis. Epidemiology 23(4), 583593 (2012)

32. van Baal, P.H., Wong, A.: Time to death and the forecasting of macro level health care expenditures: Some further consider ations. J. Health Econ. 31(6), 876887 (2012)

33. von Gaudecker, H. M., Scholz, R.: Differential mortality by lifetime earnings in Germany. Demographic Research. 17(4), 83108 (2007)

34. Werblow, A., Felder, S., Zweifel, P.: Population ageing and health care expenditure: A school of red herrings? Health Econ. 146(10), 11091126 (2007)
35. Yang, Y., Schulhofer Wohl, S., Fu, W., Land, K.: The intrinsic estimator for age period cohort analysis: What it is and how to use it. Am. J. Sociol. 113(6), 16971736 (2008)

36. Zweifel, P., Felder, S., Meier, M.: Ageing of population and health care expenditure: a red herring?. Health Econ. 8(6), 485496 (1999)

37. Zweifel, P., Felder, S., Werblow, A.: Population ageing and health care expenditure: New evidence on the red herring. Gen eva Papers Risk Insur. Issues Pract. Spec. Issue Health Insur. 29(4), 652666 (2004)

38. Zweifel, P., Steinmann, L., Eugster, P.: The Sisyphus syndrome in health revisited. Int. J. Health Care Financ. Econ. 5(2), 127145 (2005) 